\title{
Design of Overall Slope Angle and Analysis of Rock Slope Stability of Chadormalu Mine Using Empirical and Numerical Methods
}

\author{
Mahdi Rasouli Maleki ${ }^{1^{*}}$, Mohammad Mahyar², Kambiz Meshkabadi ${ }^{3}$ \\ ${ }^{1}$ Engineering Geology \& Rock Mechanic Department, Tunnel Consulting Engineers, Tehran, Iran \\ ${ }^{2}$ Mining Engineering, Tunnel Consulting Engineers, Tehran, Iran \\ ${ }^{3}$ Lecturer of Civil Engineering Department, Islamic Azad University of Ahar, Iran \\ E-mail: "Mahdi.Rasouli@yahoo.com \\ Received March 15, 2011; revised August 14, 2011; accepted August 26, 2011
}

\begin{abstract}
In engineering projects associated with rock mechanic science like open pit mines, assessment and slope stability of mine walls is one of the important performance in generate of these structures. Estimating and knowledge of stable slope angle is one of main parts that should be occurring to special attention in open pit mines studies phase. Considering the importance of economic costs in mining issues, the need for appropriate design slope angle that can cause an adverse minimize project costs and throws the other hand, the stability conditions in the safe walls of the mine life will provide essential and seems obvious. Therefore, in this study to determine the optimal slope angle of overall and bench of west wall of the Chadormalu ore iron mine, has been trying, first, done field studies on the discontinuity of western wall, engineering classification and geomechanical properties of rock masses of wall, then assess the amount of optimal slope angle using empirical method. Finally, in order to ensure stability and accuracy of the wall slope angle based on the obtained (empirical method) tries to analysis is amount of Factor of Safety (FOS), displacements and mean stress condition atwalls calculated from drilling use Phase2D powerful software.
\end{abstract}

Keywords: Overall Slope Angle, Phase2D Software, Factor of Safety (FOS)

\section{Introduction}

The purpose of this study is to determine the bench slope angle and overall slope of the west wall in Chadormalu mine in points susceptible to rupture. To do so, the survey tries to; first, detect sensitive points by current empirical methods. Then it determines the bench and overall angle of slope.

In order to be sure about the results validity obtained by the empirical methods, the study attempts to analyze stability and determine the slope safety factor and the wall displacements using finite element method and powerful Phase2D software.

\section{Position and Geology of the West Wall of the Mine}

Chadormalu iron ore mine is located in central Iran and in northern slope of Chah-Mohammad grey mountains in southern margin of Saghand salt marsh about $180 \mathrm{~km}$ from north-east of Yazd and $300 \mathrm{~km}$ from south of Tabas desert. According to the geology studies performed in this region, it was cleared that Chadormalu fault between the plain and high lands is the major factor of ore creation and mineralization in the region formed in two forms of northern and southern anomaly. Also, petrography studies on the mine rocks shows that major rocks in Chadormalu mine area are Metasomatite, Albitite, Diorite, Magnetite and Hematite[4,5]. It should be mentioned that, performance of different faults in this area makes the mine rocks tobe severely tectonizedand provide suitable conditions fordifferent ruptures of the wall.

The western wall of this mine is made up of igneous rocks and various metamorphic rocks such as Diorite, Albitite and Metasomatite[4]. Generally speaking, Figure 2 shows the geological profile perpendicular in the western wall of the mine together with its lithological combination. 


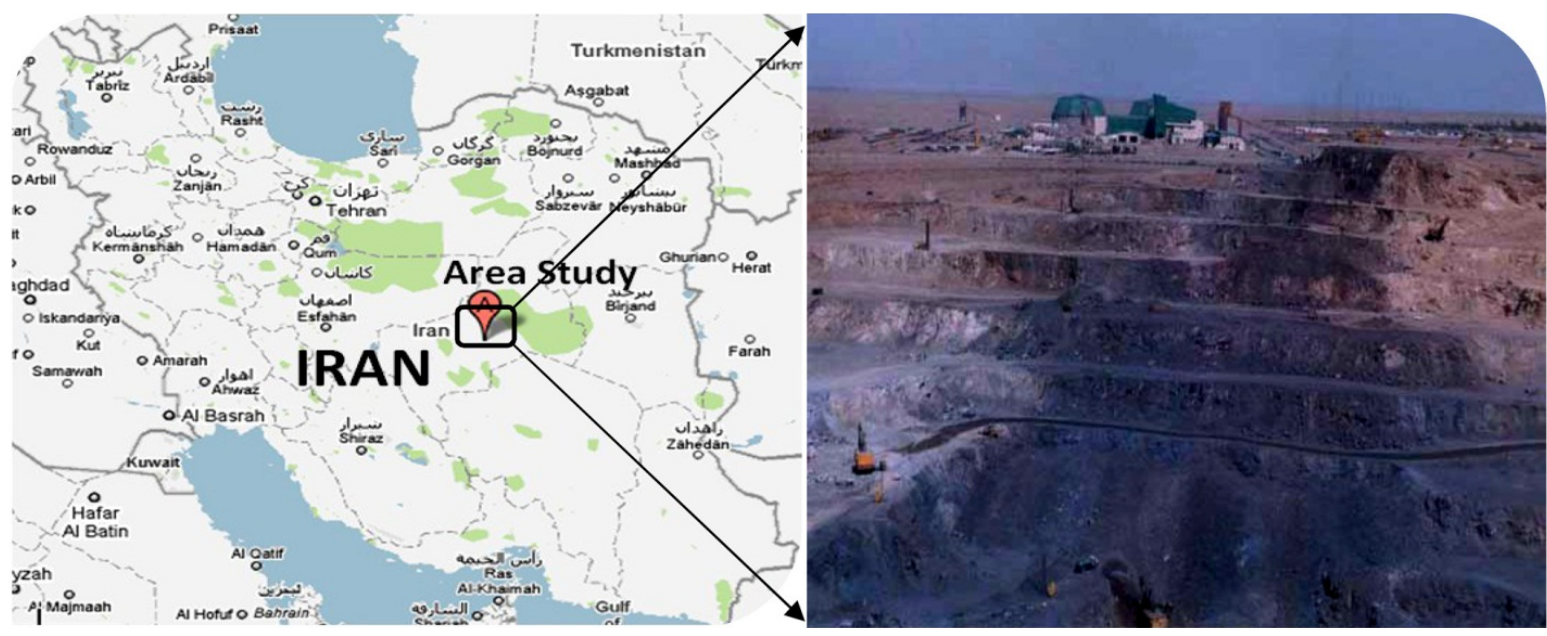

Figure 1. Location of area study on the Iran map.

\section{Profile on the midcourse of block 11 \& Block 12}

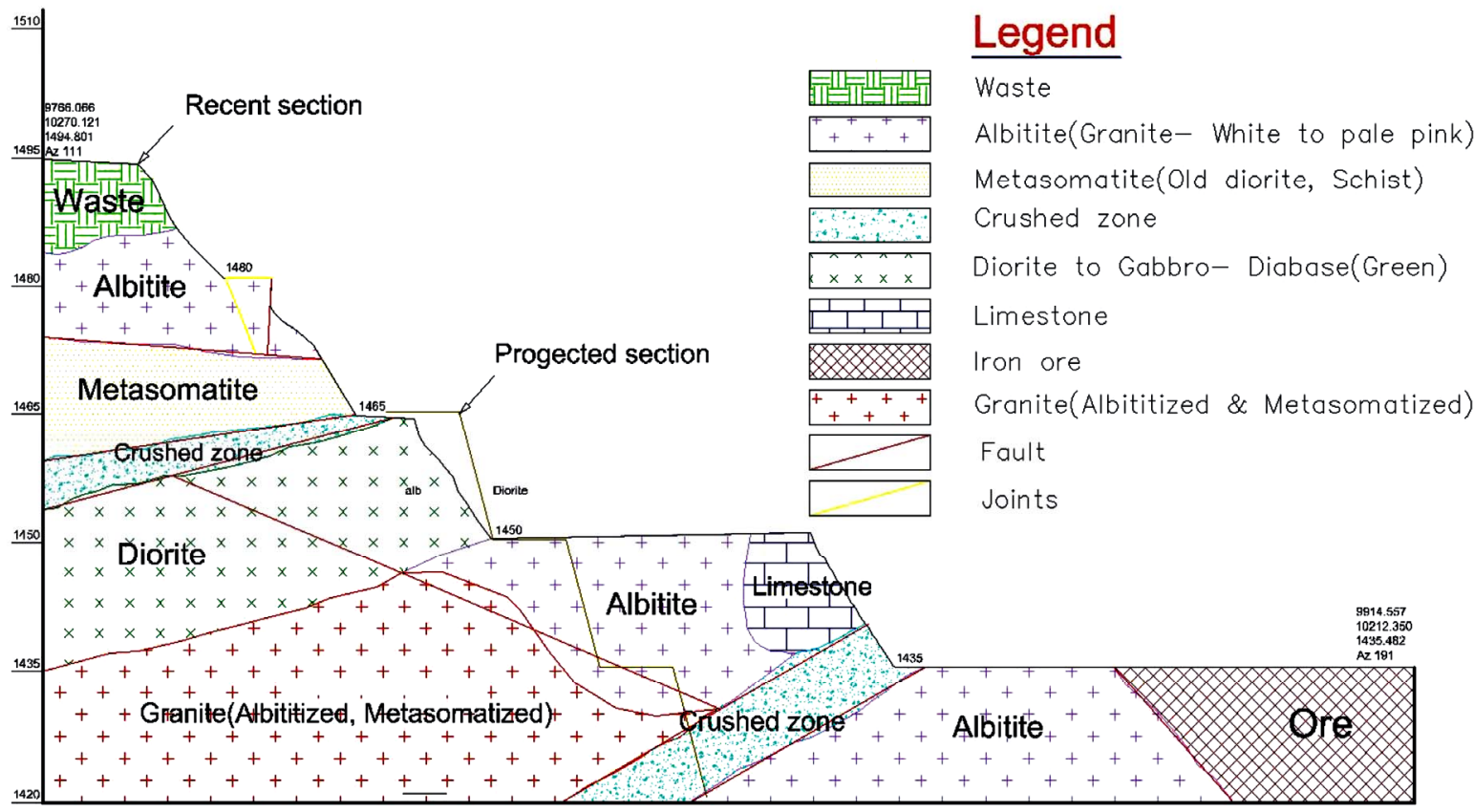

Figure 2. The geological profile perpendicular on the west wall of Chadormalu iron ore mine.

In this study, in order to save time and costs, three blocks (No. B-10, B-11, and B-13) in instability intensity wear detected as the conclusion of the geological surveys on the mine western wall, than engineering surveys and joint studies ware done on each of these blocks [5].

\section{Classification of Rock Mass and Determination of Engineering Parameters}

As the main purpose of engineering projects is to use classification systems to determine geomechanical characteristics of rocks by simple methods, this study tries to do joint studies on present discontinuities; and then it classifies the rocks enclosed in each of the blocks using Rock Mass Rating (RMR), Geological Strength Index (GSI) and Slope Rock Mass Rating (SRMR) classification systems [3]. Table 1 indicates the results of the classification of the rocks of the western wall in Chadormalu iron ore mine.

Results obtained from this table indicate that the quality of the rocks in the west wall area in Chadormalu mine is poor due to breakings and development of lots of joints and fractures.

As in engineering works especially in analysis of rock 
slopes, the purpose is to classify rocks to estimate and measure their engineering and geomechanical features correctly, this study uses results of rocks classification and Roclab software [6] for each of the rock pieces enclosed in block B-11 to detect those pa- rameters that have been introduced by empirical methods established by researches throughout the world. Table 2 shows the most important calculated engineering pa- rameters which are used in Phase2D software [7].

\section{Determination of Bench Slope and Overall Slope}

According to definition of slope geometry, it is said that height, width, and angle of bench slope are the most significant geometrical parameters of slopes and steep sur- faces where any alternation each of these features can put a direct effect on the slope stability. On the basis of these words, therefore, one can admit that optimum determination of these geometrical features of a slope in preventing rupture is one of most important parts of rock and soil slopes analysis, so that importance of this issue in open pit mine activities and road cuttings are observable and understandable [2].

This study tries to apply not only ranking system, but also other empirical methods in determination of bench slope and overall steep of the slope in order to promote the obtained results safety factor. Therefore, value of the rocks of each block, one can determine slope steep angle by the empirical methods obtained from Rock Mass Rating (RMR), Mine Rock Mass Rating (MRMR) and Slope

Table 1. Results of the classification of the west wall Chadormalu mine according to various classification systems.

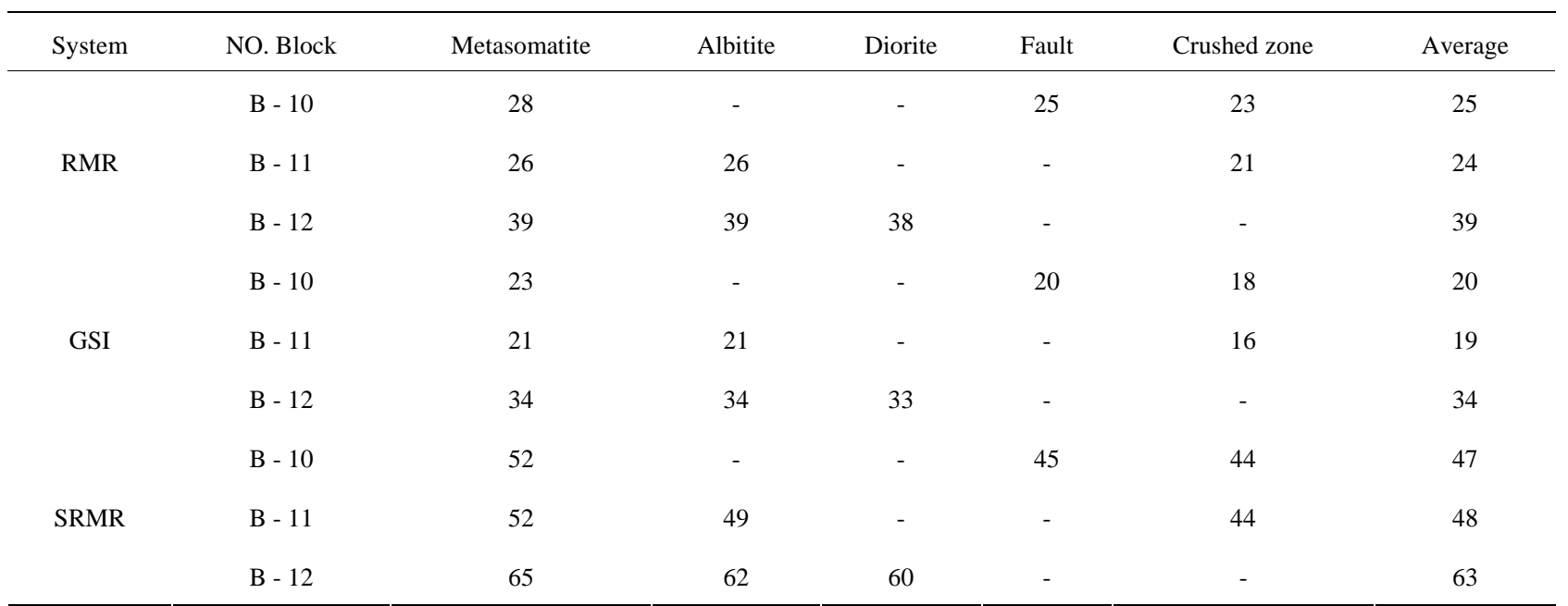

Table 2. The most important engineering parameters of each rock groups.

\begin{tabular}{|c|c|c|c|c|c|}
\hline Material & Albitite & Metasomatite & Granite & Diorite & Crushed zone \\
\hline Unit weight $\left(\mathrm{MN} / \mathrm{m}^{3}\right)$ & 0.024 & 0.028 & 0.024 & 0.028 & 0.026 \\
\hline Compressive Strength of Rock mass (MPa) & 2.29 & 2.52 & 3.24 & 3.31 & 1.83 \\
\hline Young's modulus (MPa) & 1632 & 1691 & 3901.5 & 3270 & 1268 \\
\hline Tensile strength (MPa) & 0 & 0 & 0 & 0 & 0 \\
\hline Peak friction angle (degrees) & 27.1 & 26 & 56.1 & 33.5 & 22.2 \\
\hline Peak cohesion (MPa) & 0.67 & 0.68 & 0.21 & 1.01 & 0.54 \\
\hline Dilation Angle (degrees) & 0 & 0 & 0 & 0 & 0 \\
\hline Residual Friction Angle (degrees) & 27.1 & 26 & 56.1 & 33.5 & 22.2 \\
\hline Residual Cohesion (MPa) & 0.67 & 0.68 & 0.21 & 1.01 & 0.54 \\
\hline
\end{tabular}


Rock Mass Rating (SRMR) values. Results on overall angle and safe bench slope angle for each block are shown in Tables 3 and 4 respectively. Also, Table 5 indicates features and final geometry of the west wall in Chadormalu mine.

\section{Stability Analyses of the Mine West Slope}

\subsection{Introduction}

Today, there are several methods for slope stability analysis, each has its own advantages and disadvantages. Numerical analyses methods are the most common ones that are used for rock and soil slope analyses. One of the software's that can analyze rock slope stability in a numerical way is a powerful software called Phase2D. This software was used in the present study for analyses of stability in the west wall of Chadormalu mine.

\subsection{Hypotheses of Analyses}

In this research, it is supposed the all analyses have been done in conditions prior to excavation of berm 1435 and for both static and dynamic states whit $0.31 \mathrm{~g}$ earthquake acceleration.

\subsection{Analyses and Results of the Slope Stability}

Modeling and bordering the concerned slope in finite element Phase2D software and running the program, result of stability in the west slope of the mine were examined. The results show that safety factor of the slope designed under static and dynamic conditions will be 3.39 $\mathrm{m}$ and $2.26 \mathrm{~m}$, respectively (Table 6). Also, displacement due to berms excavation is $1.5 \mathrm{~cm}$ for static state and 1.6 $\mathrm{cm}$ for dynamic one. Figures 3 and $\mathbf{4}$ represents the outcome model of Phase2D software (Factor of safety, total displacement and mean stress status) in condition prior to excavation of bench 1435 and Figure 5 shows the shear-strain changes for both static and dynamic states, respectively.

\section{Conclusions}

Results obtained from this study confirm that; in dynamic condition, to obtain a safety factor upper than 2.2, the bench slope angle and its overall slope angle should

Table 5. Features and final geometry obtained for bench for the west wall in Chadormalu mine.

\begin{tabular}{cc}
\hline Slope Parameters & Value \\
\hline High (m) & 15 \\
Width of bream (m) & 8.5 \\
Bench Angle (degree) & 70 \\
Inter-ramp Angle (degree) & 47 \\
Overall Angle (degree) & 44 \\
\hline
\end{tabular}

Table 6. Slope safety factor and displacement due to slopes excavation.

\begin{tabular}{ccc}
\hline Parameters & Static & Dynamic \\
\hline Safety of Factor (SRF) & 3.39 & 2.26 \\
Horizontal displacement (m) & 0.015 & 0.016 \\
\hline
\end{tabular}

Table 3. Safe overall slope angle obtained by Bieniawski (1989)[1] method.

\begin{tabular}{|c|c|c|c|c|c|c|}
\hline NO. Block & Metasomatite & Albitite & Diorite & Fault & Crushed zone & Average \\
\hline B - 10 & 45.6 & - & - & 41.7 & 38.7 & 42.0 \\
\hline B - 11 & 42.6 & 42.6 & - & - & 35.0 & 40.1 \\
\hline B -12 & 57.4 & 57.4 & 56.5 & - & - & 57.1 \\
\hline
\end{tabular}

Table 4. Safe bench slope angle obtained by Slope Rock Mass Rating (SRMR).

\begin{tabular}{ccccccc}
\hline NO. Block & Metasomatite & Albitite & Diorite & Fault & Crushed zone & Average \\
\hline B - 10 & 69 & - & - & 66 & 65 & 66 \\
B - 11 & 69 & 67 & - & - & 65 & 67 \\
B - 12 & 74 & 73 & 72 & - & - & 73 \\
\hline
\end{tabular}




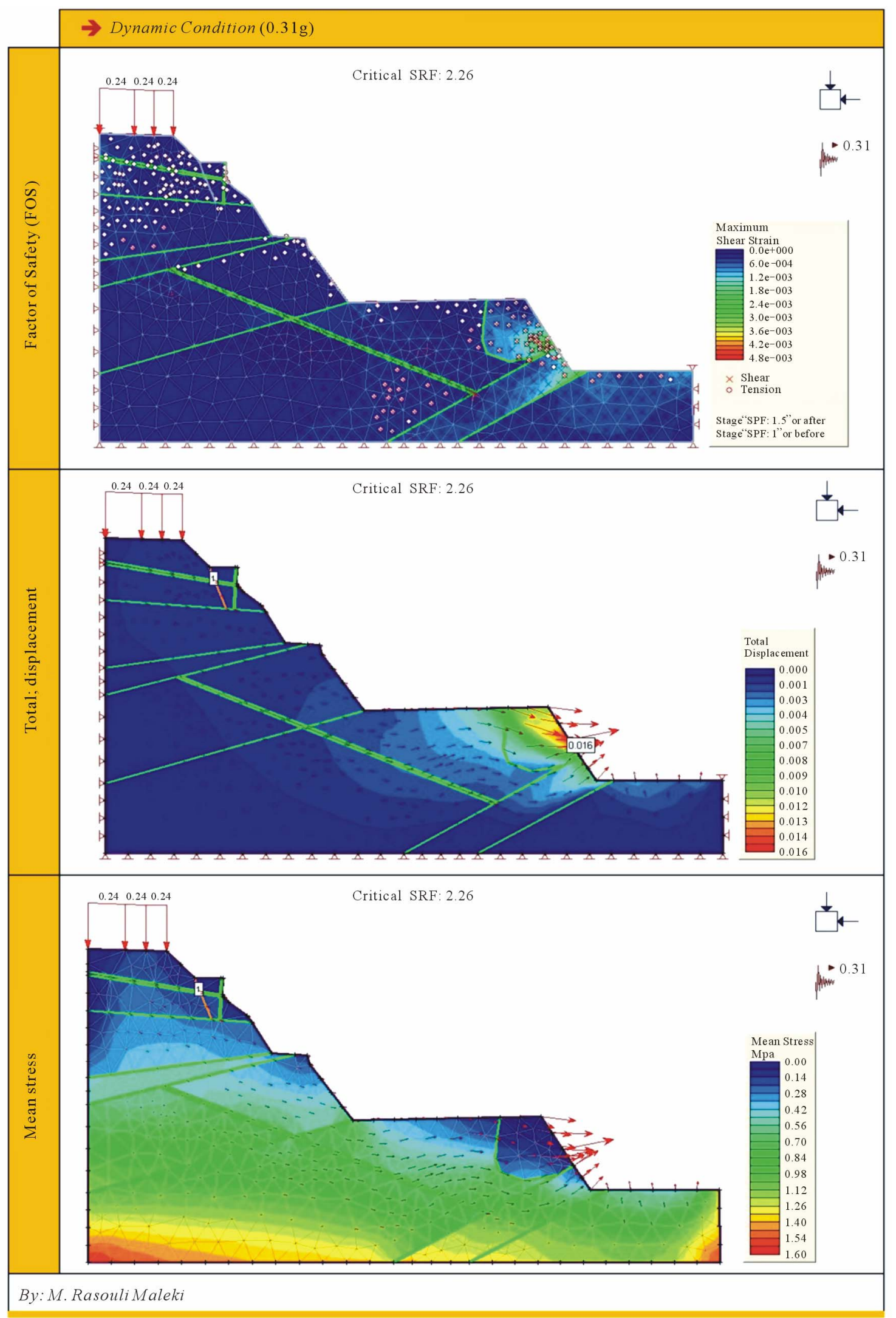

Figure 3. Output model of Phase2D software, factor of safety (FOS), total displacements and mean stress for static state. 


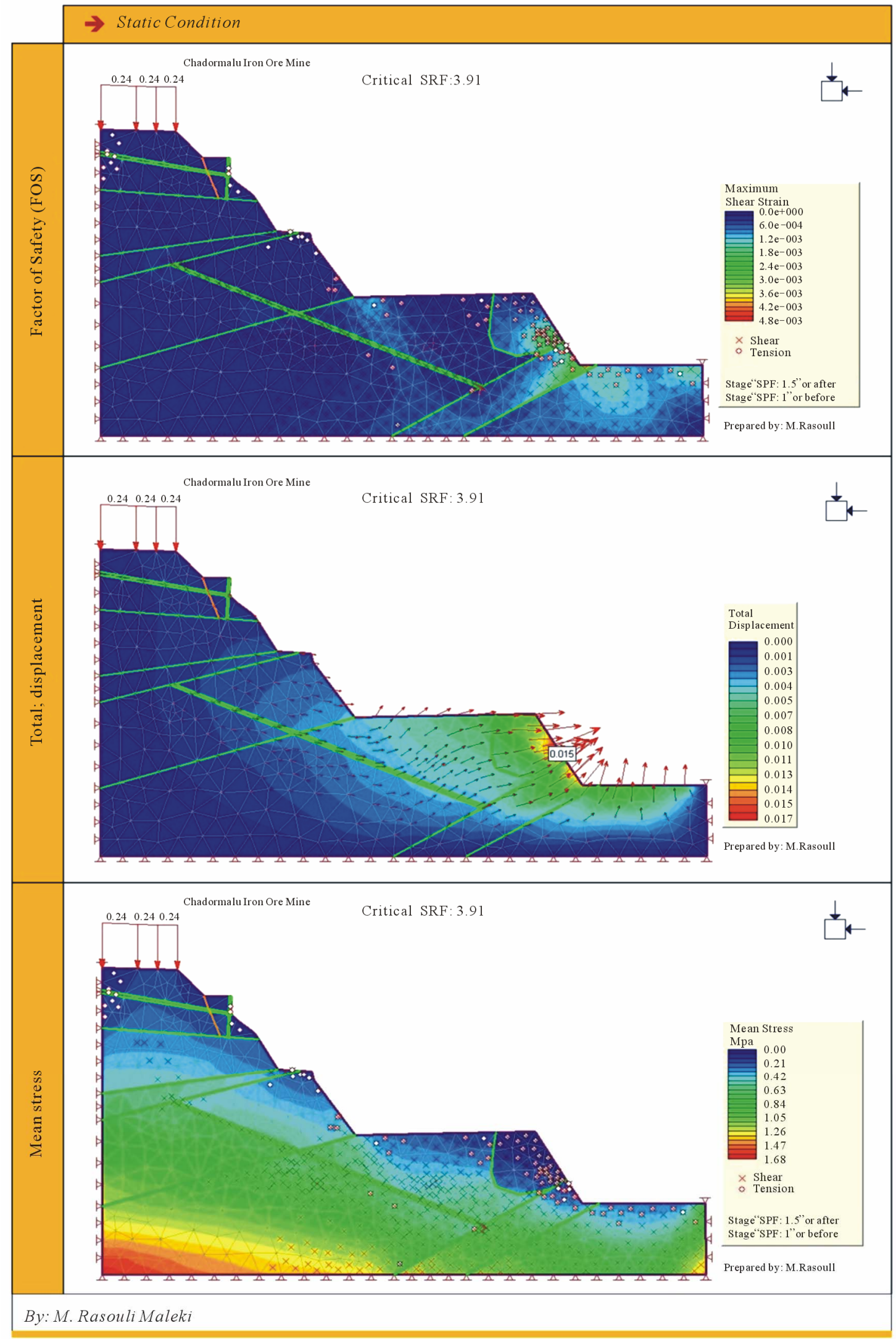

Figure 4. Output model of Phase2D software, factor of safety (FOS), total displacements and mean stress for dynamic state. 


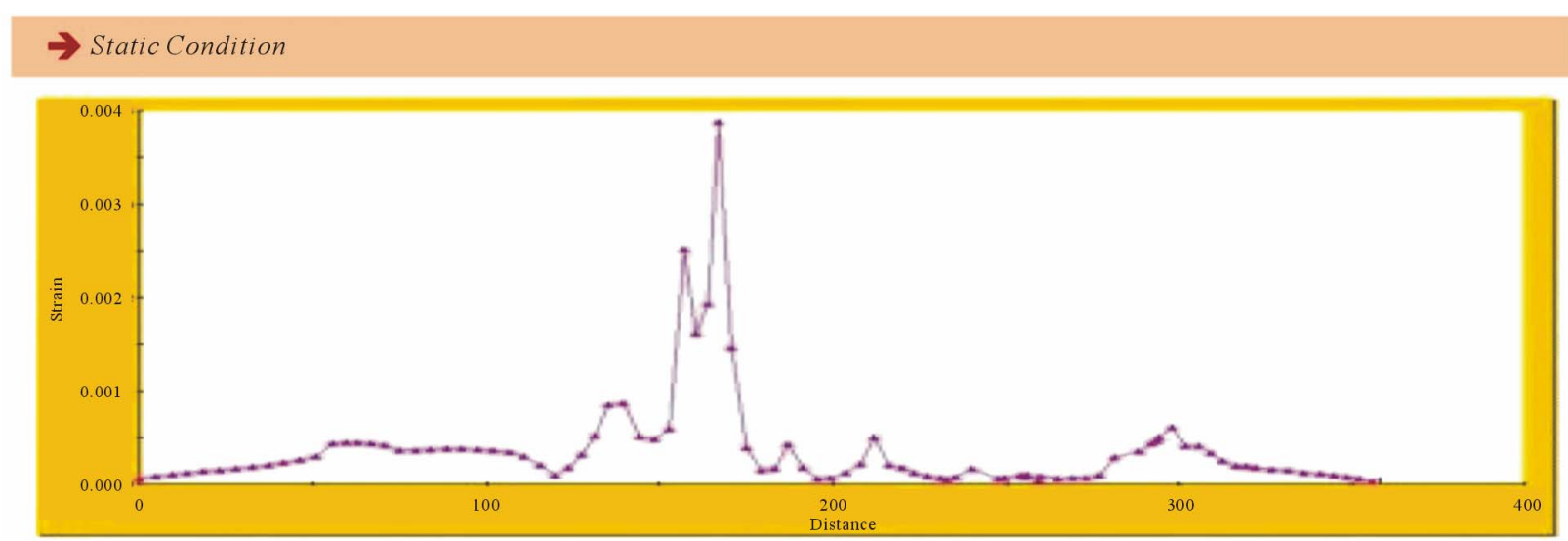

Dynamic Condition $(0.31 \mathrm{~g})$

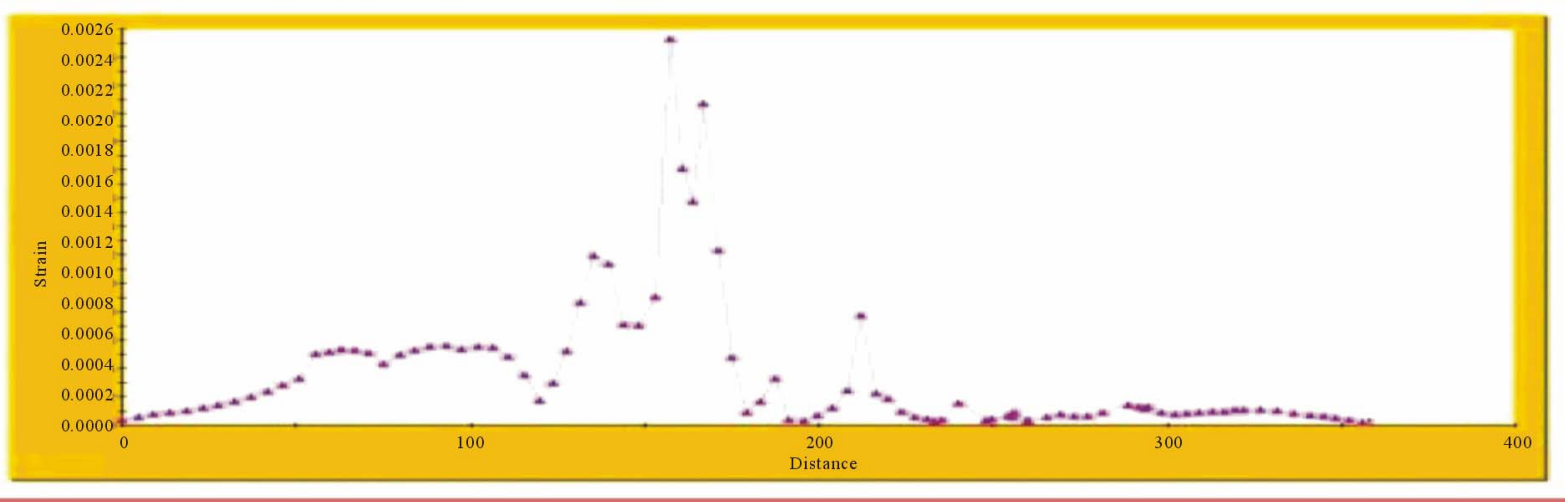

Figure 5. Shear-strain changes for static and dynamic states.

be 70 degree and 44 degree. Also, according to the features of the rock masses in this area, numerical analysis results indicate that; under such a condition, displacement due to bench excavation will be led than $1.5 \mathrm{~cm}$.

\section{References}

[1] Z. T. Bieniawski, "Engineering Rock Mass Classifications,” Wiley, New York, 1989, pp. 5-249.

[2] M. Rasouli, "Study of the Engineering Geological Problems of the Havasan Dam, with Emphasis on ClayFilled Joints in the Right Abutment," International Journal of Rock Mechanics and Rock Engineering, 2011, pp. 1-16. doi:10.1007/s00603-011-0165-2

[3] M. Rasouli and M. Mahyar, "Assessment of Dominant Type of Failures in the Cutting of Transit Road Iran Armenia Based on SMR Classification System," 4th
National Conference on Rock Mechanics, Iran, 2011.

[4] M. Rasouli and M. Mahyar, “Assessment and comparison of occurring probability of rock failures based on empirical and kinematical methods," 4th National Conference on Rock Mechanics, Tehran, May 2011.

[5] M. Rasouli, “Assessment of Occurrence Probability for Planar \& Wedge Failures under Dynamic \& Static Conditions in Abutments of a Double Arch Concrete Dam (Case Study)," 4th International Conference on Geotechnical Engineering and Soil Mechanics, Tehran, 2-3 November 2010.

[6] Roc Science, Rock Mass Strength Analysis Using the Hoek-Brown failure criterion, 2005.

[7] Roc Science, Two-Dimensional Finite Element Slope Stability Analysis, 2005 